\title{
Journal of Clinical Respiratory Diseases and Care
}

\section{Risk Factors Associated with Asthma among Saudi Adults in Najran}

\section{Elfaki NK ${ }^{1^{*}}$ and Shiby $\mathrm{AY}^{2}$}

${ }^{1}$ Community Health Nursing Department, Nursing College, Najran University, Saudi Arabia

${ }^{2}$ Dept. of Medical-Surgical Nursing, Nursing College, Najran University, Saudi Arabia

*Corresponding author: Elfaki NK, Community Health Nursing Department, Nursing College, Najran University, Saudi Arabia, Tel: (00966) 5031 51008; E-mail: nahid1768@hotmail.com

Received date: October 24, 2017; Accepted date: November 15, 2017; Published date: November 22, 2017

Copyright: (C) 2017 Elfaki NK, et al. This is an open-access article distributed under the terms of the Creative Commons Attribution License, which permits unrestricted use, distribution, and reproduction in any medium, provided the original author and source are credited.

\begin{abstract}
Background: Asthma is a chronic illness that affects people of all ages. Its prevalence has risen over the last few decades in Saudi Arabia. The aim of this study was to explore the common risk factors that associated with asthma among Saudi adults in Najran during the period December 2016 to October 2017. One hundred eighty four patients who were over 18 years of age and who had a diagnosis of definite asthma (cases), beside another 184 healthy individuals as control group, that matched the cases in terms of age and sex constituted the study sample. A questionnaire as a tool of data collection was completed by cases as well as from controls. It was consisting of data that include personal, familial and indoor environmental factors that could be potential risk factors for asthma. The mean ages for cases and controls were $21.3( \pm 16.5)$ and $21.7( \pm 16.8)$ years respectively. Each group consisted of $108(58.7 \%)$ males beside $76(43.3 \%)$ females. There were no significant association between asthma occurrence and level of education and indoor plants with P-value $>0.05$. On the other hand, multivariate logistic regression analysis showed that family history $(\mathrm{OR}=5.01$ and $\mathrm{Cl}=2.09-8.42)$, using sprays of insecticides or air fresheners $(\mathrm{OR}=8.5, \mathrm{Cl}=2.34-11.09)$, as well as rhinitis $(\mathrm{OR}=4.76, \mathrm{Cl}=2.19-6.45)$ were significantly associated with asthma occurrence. Additionally, active or passive smoking was significantly ( $P$-value $=0.041$ and 0.012 ) associated with asthma among adults in Najran. It was concluded that family history, smoking, allergic rhinitis and smoking among the most risk factors for developing asthma among Saudi adults. Further studies for investigating other factors were recommended. Moreover, health education programs for educating people about the risk factors, preventive measures, early diagnosis and proper management were highly recommended.
\end{abstract}

Keywords: Asthma; Allergy; Risk factors; Saudi adults

\section{Introduction}

Asthma is a major health problem worldwide that occurs at any age, although it is more common among people under 40 years old. It has been estimated globally that 300 million persons suffer from asthma $[1,2]$. Asthma is a complex chronic inflammatory condition of the airways, which makes breathing difficult, and characterized by variable reversible and recurring symptoms related to airflow obstruction, bronchial hyperresponsiveness and an underlying inflammation [3]. Its development is seen as an intricate interaction between genetic and environmental factors [4]. It manifests in a variety of symptoms such as cough, wheezes, chest tightness and shortness of breathing $[5,6]$.

Asthma is one of the most common chronic diseases in Saudi Arabia (KSA), it affects more that 2 million Saudis, and local reports suggest that the prevalence of asthma in Saudi Arabia is increasing [3].

Asthma continues to have a major impact on public health globally. Although, there is still an unacceptable level of morbidity, but fortunately, death from asthma is infrequent [7].

Its impact goes beyond the patients to their families as well as to the community as a whole in terms of lost work and school days, poor quality of life, frequent emergency department visits, hospitalizations and death cases may occur $[3,8]$.

An asthma attack can occur when someone with asthma is exposed to certain environmental triggers. Asthma triggers vary from person to person. However, some common asthma triggers include tobacco smoke, dust mites, cockroach allergens, pet, mold and wood smoke [9].

Despite the fact that the Saudi Thoracic Society (STS) is committed to a long-term enhancement plan for the best practice in the asthma field by creating asthma guidelines, periodic scientific meetings, frequent asthma courses and educational brochures, but local reports suggest that the prevalence of asthma is increasing in Saudi Arabia, this could be due to environmental changes, beside exposure to indoor and outdoor allergens as well as occupational and industrial exposure [10].

Additionally, KSA ministry of health had launched several programs to promote awareness about asthma. Asthma Insights and reality in the Kingdom of Saudi Arabia (AIRKSA) was launched in 2008 to determine the level of asthma control among asthmatic people [11]. Another asthma initiative was launched in 2009 to promote best practices in asthma management [12]. Although it is too early to tell the impact of those programs, clearly there is a need for a comprehensive survey for assessing the outcomes of these programs.

Asthma comprises a range of heterogeneous phenotypes that differ in presentation, etiology and pathophsiology. Risk factors for each recognized phenotype of asthma include genetic, environmental and host factors. Although a family history of asthma is common, it is neither sufficient nor necessary for the development of asthma [13].

A plethora of risk factors have been shown to contribute to asthma. Risk factors may increase the chance of developing asthma, or may increase the chance that a person with asthma will develop additional health problems [7]. These factors can be classified as indoor or 
outdoor allergens and air pollutants in terms of environmental and psychological factors [14]. The most important indoor air pollutant is related to tobacco (smoking) exposure, over usage of detergents and other domestic insecticides, furred animals and cockroaches $[5,15]$. Most of the interventions to reduce exposure to these triggers are helpful, but likely alone, will not help to achieve asthma control [7]. On the other hand, outdoor allergens such as pollens and molds are impossible to avoid completely. Very interesting, food and food additives are uncommon triggers for asthma [16].

\section{Materials and Methods}

This is a descriptive, cross-sectional and facility based study that was carried out among adult asthmatic Saudi patients who were attending outpatient thoracic clinic at King Khaled Hospital at Najran, KSA, during the period of December, 2016 and October, 2017.

One hundred eighty four patients (cases) who were 18 years old or above and who had a diagnosis of definite asthma, beside another 184 healthy persons (controls) that matched the patients in age and sex constituted the study sample. Informed verbal consent and confidentiality were assured for the participated individuals who agreed voluntary in this study after receiving enough information. A questionnaire was completed from cases as well as from controls for collecting data, that including personal, familial, indoor and outdoor environmental factors that may be potential risk factors to asthma. The sample size was designated to ensure confidence level of $95 \%$, with an error margin of 0.05 .

\section{Data analysis}

A semi-structured questionnaire was used for collecting data. Data include socio-demographic characteristics beside family history and smoking status. Data were collected and entered into SPSS software
(Statistical Package for Social Science), version 18. Chi-square test was used to compare differences in proportions between groups (Odds ratios with $95 \%$ confidence intervals). Differences at $5 \%$ level (P value $\leq 0.05)$ were considered significant.

\section{Results}

A total sample of 184 cases that were 18 years old or above and who had a diagnosis of definite asthma beside another 184 healthy persons as control group that matched the cases in age, sex and educational levels were recruited to participate in this study. Each group consists of 108 males (58.7\%), beside $76(41.3 \%)$ females. The mean age of cases and controls were $21.3( \pm 16.5)$ and $21.7( \pm 16.8)$ respectively. The majority of cases and controls (45.7\%) aged between $18-29$ years old, beside that only $17.4 \%$ of them were singles as shown in Table 1 . As displayed in Figure 1, the majority of cases (48\%) were currently active smokers, compared with controls that only $35 \%$ of them were active smokers, which indicates strong association between asthma and smoking.

The results of this study revealed that there were no significant association between asthma occurrence and level of education with $\mathrm{P}$ value $>0.05$. Although about $64.1 \%$ of cases and $46.7 \%$ of controls \{Confidence Interval (CI) 1.23-4.91\} reported that they have plants and/or flowers in their homes, but no significant association was found between asthma and presence of indoor plant (P-value $>0.05)$. On the other hand, multivariate logistic regression analysis showed that family history $\{$ Odds Ratio $(\mathrm{OR})=5.01$ and Confidence Interval $(\mathrm{CI})=2.09$ $8.42\}$, using of spray insecticide/air freshener $(\mathrm{OR}=8.5, \mathrm{CI}=2.34-$ $11.09)$, as well as rhinitis $(\mathrm{OR}=4.76, \mathrm{CI}=2.19-6.45)$ were significantly associated with asthma occurrence as shown in Table 2. Additionally, active or passive smoking was significantly ( $\mathrm{P}$-value $=0.041$ and 0.012 ) associated with asthma among adults in Najran as presented in Table 3.

\begin{tabular}{|c|c|c|c|}
\hline Variable & Characteristics & Frequency $(50 \%+50 \%$ controls $)$ & Percentage \\
\hline \multirow[b]{3}{*}{ Age } & $18-29$ & 168 & $45.70 \%$ \\
\hline & 30-39 & 110 & $29.90 \%$ \\
\hline & $\geq 40$ & 90 & $24.50 \%$ \\
\hline \multirow[b]{2}{*}{ Sex } & Male & 216 & $58.70 \%$ \\
\hline & Female & 152 & $41.30 \%$ \\
\hline \multirow[b]{3}{*}{ Marital status } & Single & 64 & $17.40 \%$ \\
\hline & Married & 234 & $63.60 \%$ \\
\hline & Divorced /Widowed & 70 & $19 \%$ \\
\hline \multirow[b]{2}{*}{ Employment status } & Employee & 228 & $62 \%$ \\
\hline & HW/no job & 140 & $38 \%$ \\
\hline \multirow[b]{4}{*}{ Educational status } & Uneducated (illiterate) & 32 & $8.70 \%$ \\
\hline & Primary or intermediate school & 144 & $39.10 \%$ \\
\hline & Secondary school graduate & 164 & $44.60 \%$ \\
\hline & University or higher education & 28 & $7.60 \%$ \\
\hline
\end{tabular}

Table 1: Demographic profile of the selected sample $\{\mathrm{n}=368$ (184 cases +184 controls $)\}$. 
Citation: Elfaki NK, Shiby AY (2017) Risk Factors Associated with Asthma among Saudi Adults in Najran. J Clin Respir Dis Care 3: 133. doi:

Page 3 of 5

\begin{tabular}{|c|c|c|c|c|c|}
\hline Factors & Cases no (\%) & Controls no (\%) & Odds Ratio (OR) & Confidence Interval (Cl) & P-value \\
\hline \multicolumn{6}{|l|}{ Educational level } \\
\hline Uneducated (Illiterate) & $20(10.9 \%)$ & $12(6.5 \%)$ & 1.01 & - & \multirow[b]{4}{*}{0.13} \\
\hline Primary or intermediate school & $75(40.8 \%)$ & $69.37 .5 \%)$ & 0.42 & $0.48-2.12$ & \\
\hline Secondary school & $77(41.8 \%)$ & $87(47.3 \%)$ & 1.06 & $0.36-2.09$ & \\
\hline University or higher education & $12(6.5 \%)$ & $16(8.7 \%)$ & 1.03 & $0.39-2.61$ & \\
\hline \multicolumn{6}{|l|}{ Family history } \\
\hline Yes & $123(66.8 \%)$ & $74(40.2 \%)$ & 5.01 & $2.09-8.42$ & \multirow[b]{2}{*}{$<0.05^{\star}$} \\
\hline No & $61(33.2 \%)$ & $110(59.8 \%)$ & & & \\
\hline \multicolumn{6}{|l|}{ Indoor plants/flowers } \\
\hline Yes & $118(64.1 \%)$ & $86(46.7 \%)$ & 2.41 & $1.23-4.91$ & \multirow[b]{2}{*}{0.07} \\
\hline No & $66(35.9 \%)$ & $98(53.3 \%)$ & & & \\
\hline \multicolumn{6}{|c|}{ Using insecticides/ air fresheners (spray) } \\
\hline Yes & $74(40.2 \%)$ & $68(37 \%)$ & 8.5 & $2.34-11.09$ & \multirow[b]{2}{*}{$<0.05^{*}$} \\
\hline No & $110(59.8 \%)$ & $116(63 \%)$ & & & \\
\hline \multicolumn{6}{|l|}{ History of allergic Rhinitis } \\
\hline Yes & $99(53.8 \%)$ & $102(55.5 \%)$ & 4.76 & $2.19-6.45$ & \multirow[b]{2}{*}{$<0.05^{*}$} \\
\hline No & $85(46.2 \%)$ & $82(44.6 \%)$ & & & \\
\hline
\end{tabular}

Table 2: Multivariate logistic regression analysis $\{\mathrm{n}=368$ (184 cases +184 controls) $\}$.

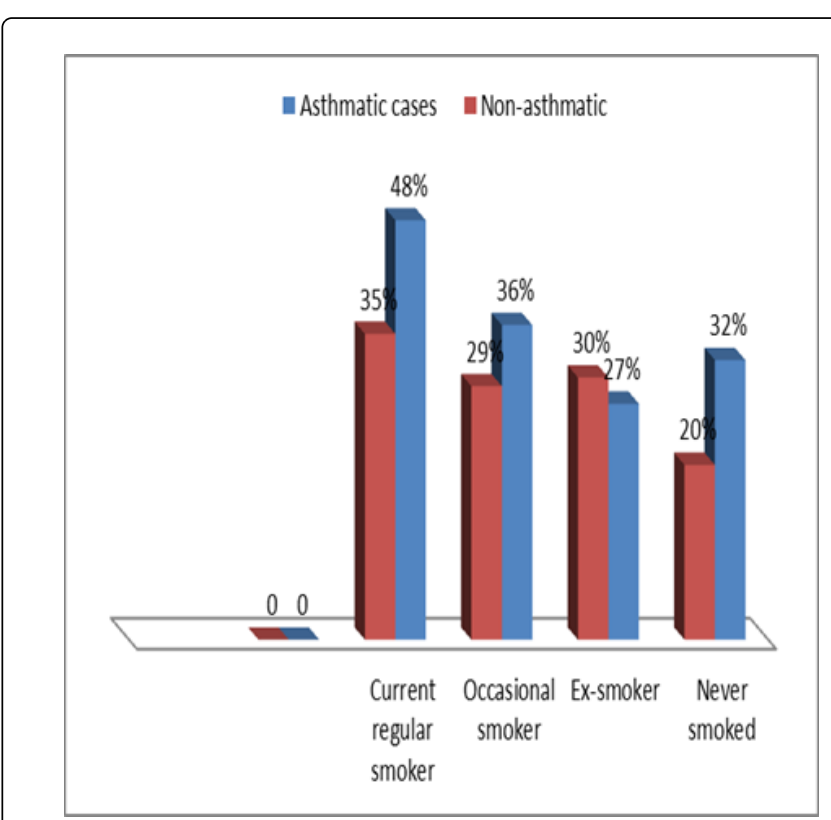

Figure 1: Smoking status for the studied sample for cases and controls.

\begin{tabular}{|l|l|l|l|l|}
\hline \multirow{2}{*}{ Variables } & \multicolumn{2}{|l|}{ Asthma status No (\%) } & X2 & \multicolumn{1}{|c|}{$\begin{array}{c}\text { P } \\
\text { value }\end{array}$} \\
\cline { 2 - 5 } & Cases & Controls & \multicolumn{2}{|c|}{-} \\
\hline Active smoker & $49(26.6 \%)$ & $\begin{array}{l}42 \\
(22.8 \%)\end{array}$ & 1.77 & $0.041^{*}$ \\
\hline Secondhand (passive) smoker & $\begin{array}{l}122 \\
(66.3 \%)\end{array}$ & $103(56 \%)$ & 0.86 & $0.012^{*}$ \\
\hline Neither active, nor passive smoker & $13(7.1 \%)$ & $\begin{array}{l}39 \\
(21.2 \%)\end{array}$ & 1.01 & 0.063 \\
\hline *Correlations considered significant when P-value <0.05
\end{tabular}

Table 3: Association between smoking status and asthma among cases and controls.

\section{Discussion}

Asthma is a chronic inflammatory disease of the airways, which makes breathing difficult. Many cross-sectional studies have confirmed increases in the incidence and prevalence of asthma over the past 2-3 decades, but much remains unknown as to the fundamental immunologic, genetic and environmental mechanisms underlying the development of this condition, especially in the developed world [17].

The current study revealed that allergic rhinitis increases the risk for developing asthma, which is in consistent with what was concluded by 
Page 4 of 5

Zhao et al. who reported that asthma is significantly associated allergic rhinitis [18]. Several other studies have shown similar relationship findings [19-21]. Additionally, this correlation was studied in large for 10 years-follow up study of patients with allergic rhinitis [22].

This study showed that females' cases were slightly higher than males among the total asthmatic cases within the studied sample, this obtained result is consistent with other studies that yielded similar results among adults [23-25]. In contrast, Bjerg et al. concluded that asthma was observed to be more in males than females [26]. Very interestingly, a gender variation in asthma had been studied in Nigeria which reported a weak independent association between prevalence of asthma and gender [14].

The influence of smoking and exposure to secondhand smoking had been acknowledged in many studies as one of the most important risk factor for developing asthma. Vozoris and Stanbrook believe that exposure to environmental tobacco smoke beside is an asthma trigger, it is also consistently worsens asthma symptoms [27]. Other number of studies have shown a significant association between smoking or exposure to smoke and increased risk of developing asthma $[28,29]$.

Similarly, our study shows a significant association between asthma and smoking. The same results had been reported by Cerveri et al. [30]. Moreover, Skoner stated that exposure to tobacco smoke was one of the strongest and most consistent risk factors in regard to development and exacerbation of asthma [31]. Furthermore, Larson et al. evaluated the impact of exposure to environmental tobacco smoke during childhood on asthma prevalence in adulthood and they also reported that the prevalence of physician-diagnosed asthma was higher in exposed subjects than non-exposed subjects (7.6\% and $5.9 \%$, with p-value 0.036) [32].

These findings were coincided with what was reported by Asthma Burden Report (ABR) that shows no significant association between prevalence of asthma and smoking [33].

Genetic factors too have an important effect on the inception, severity and treatment of asthma. Over the past decade, Genome-Wide Association Studies (GWASs) have been utilized extensively to analyze the genetic influences on common complex diseases, including asthma [34]. Numerous studies have reported a strong correlation between family history of asthma and increased risk of the disease $[35,36]$. In agreement with these mentioned studies, the current study shows a significant association between asthma and family history. Similar findings have been reported by other studies that showed a significant association between hereditary factor and asthma occurrence $[37,38]$.

\section{Conclusion and Recommendation}

Asthma continues to have a major impact on public health internationally. Based on the obtained results, it was concluded that there are different risk factors patterns for asthma, those factors appear to play a major role and likely contribute to the magnitude of this burden. Rhinitis, hereditary or genetic factors, tobacco use or exposure to environmental tobacco smoke are among those risk factors or trigger factors that associated with the development of asthma. Health education programs were highly recommended to reduce exposure to triggers among Saudi people.

Our observations may serve a template and thus emphasize the importance of future longitudinal studies on asthma.
The current study has some limitations that include, first of all our data was cross-sectional and therefore, we couldn't assess causality. Furthermore, some behavioral data for instance smoking are selfreported that subjected to recall and social desirability biases. Moreover, we reported cases on self-reported diagnosed asthma.

\section{References}

1. American Lung Association (2017) Asthma in adults. Fact sheet.

2. World Health Organization. Global surveillance, prevention and control of chronic respiratory diseases: a comprehensive approach. 2007.

3. Eder W, Ege MJ, von Mutius E (2006) The Asthma epidemic. N Engl J Med 355: 2226-2235.

4. Kumar R (2008) Prenatal factors and the development of asthma. Curr Opin Pediatr 20: 682-687.

5. Duksall F, Becerir T, Ergin A, Akcay A, Guler N (2014) The prevalence of asthma diagnosis and symptoms is still increasing in early adolescents in Turky. Allergology International 63: 189-197.

6. Shirina A, Abdishakur A, Roos B (2010) Prevalence and risk factors of Asthma among Adolescents and Their Parents in Al-Ain UAE. Respiration 79: 105-111.

7. Al-Moamary MS, Al-Hajjaj MS, Idrees MM, Zeitouni MO, Alanezi MO, et al. (2009) The Saudi Initiative for asthma. Ann Thorac Med 4: 216-233.

8. Aggarwal AN, Chaudhry K, Chhabra SK, D'Souza GA, Gupta D, et al. (2006) Prevalence and risk factors for bronchial asthma in Indian adults: A multicentre study. Indian J Chest Dis Allied Sci 48: 13-22.

9. Gilmour MI, Jaakkola MS, London SJ, Nel AE, Rogers CA (2006) How exposure to environmental tobacco smoke, outdoor air pollutants and increased pollen burdens influences the incidence of asthma. Environ Health Perspect 114: 627- 633.

10. Ministry of Health of the Kingdom of Saudi Arabia. The asthma Insights and reality in the Kingdom of Saudi Arabia (AIRKSA) study, 2007.

11. Maziar M, Charbel B, Farah D, Marwa T, Hannah K, et al. (2015) Prevalence of asthma in Saudi adults: Findings from a national household survey-2013. BMC Pulmonary Medicine 15:77.

12. Almoamary MS, Alhaider Sa, Alhajjaj MS, Al-Ghobain MO, Idrees MI, et al. (2012) The Saudi initiative for asthma- 2012 update guidelines for the diagnosis and management of asthma in adults and children. Ann Thorac Med 7: 175.

13. Traore EA (2010) "Chapter 3: Asthma Risk Factors and Co-Morbidities" Asthma Burden Report- New Hampshire.

14. Desalu OO, Fadare JO, Adeoti AO, Adekoya AO (2013) Risk factors for Asthma Hospitalization and Emergency department visit in Nigeria: The role of symptoms frequency and drug utilization. Indian J allergy Asthma Immunol 27: 129-133.

15. Nguyen K, Peng J, Boulay E (2010) Effect of smoking on the association between environmental triggers and asthma severity among adults in new England. J Asthma Allergy Educ 1: 210-218.

16. Georgy V, Fahim H, Gaafary M, Walters S (2006) Prevalence and socioeconomic associations of asthma and allergic rhinitis in Northern Africa. Eur Respir J 28: 756-762.

17. Rosenberg SL, Miller GE, Brehm JM, Celedon JC (2014) Stress and asthma: Novel insights on genetic, epigenetic and immunologic mechanisms. J Allergy Clin Immunol 134: 1009-1015.

18. Zhao TB, Wang HJ, Chen YZ, Xiao M, Duo L, et al. (2000) Prevalence of childhood asthma, allergic rhinitis and eczema in Urumqi and Beijing. J Paediatr Child Health 36: 128-33.

19. Akcakaya N, Kulak K, Hassanzadeh A, Camcioğlu Y, Cokuğraş H (2000) Prevalence of bronchial asthma in Istanbul school children. Eur J Epidemol 16: 693-699.

20. Nayak A (2003) The asthma and allergic rhinitis link. Allergy asthma proc 24: 395-402. 
Citation: Elfaki NK, Shiby AY (2017) Risk Factors Associated with Asthma among Saudi Adults in Najran. J Clin Respir Dis Care 3: 133. doi:

Page 5 of 5

21. Talay F, Kurt B, Tug T, Kurt OK, Goksugur N, et al. (2014) The prevalence of asthma and allergic diseases among adults 30-49 years of age in Bolu, Western Black Sea Region of Turkey. Clin Ter 165: 59-63.

22. Bousquet J, Gaugris S, Kocevar VS, Zhang Q, Yin D, et al. (2005) Increased risk of asthma attacks and emergency visits among asthma patients with allergic rhinitis: A subgroup analysis of the investigation of montelukast as a partner agent for complementary therapy. Clin Exp Allergy 35: 723-727.

23. Almqvist C, Worm M, Leynaert B (2008) Impact of gender on asthma in childhood and adolescence. Allergy 63: 47-57.

24. Vink NM, Postma DS, Schouten JP, Rosmalen JG, Boezen HM (2010) Gender differences in asthma development and remission during transition through puberty: The TRacking Adolescents' Individual Lives Survey (TRAILS) study. J Allergy Clin Immunol 126: 498-504.

25. Melgert BN, Ray A, Hylkema MN, Timens W, Postma DS (2007) Are there reasons why adult asthma is more common in females? Curr Allergy Asthma Rep 7: 143-150.

26. Bjerg A, Sandstrom T, Lundback B, Ronmark E (2010) Time trends in asthma and wheeze in Swedish children 1996-2006: prevalence and risk factors by sex. Allergy 56: 48-55.

27. Vozoris NT, Stanbrook MB (2011) Smoking prevalence, behaviors and cession among individuals with COPD or asthma. Respir Med J 105: 477 484.

28. Chen Y, Dales R, Tang M, Krewski D (2002) Sex-related interactive effect of smoking and household pets on asthma incidence. Eur Respir J 20: 1162-1166.
29. Piipari R, Jaakkola JJK, Jaakkola N, Jaakkola MS (2004) Smoking and asthma in adults. Eur Respir J 24: 734-739.

30. Cerveri I, Cazzoletti L, Corsico A, Marcon A, Niniano R, et al. (2012) The impact of cigarette smoking on asthma: a population-based cohort study. Int Arch Allergy Immunol 158: 175-183.

31. Skoner D (2001) Controlling asthma: why we must do better. Contemp Pediatr 18: 49-62.

32. Larson ML, Frisk M, Hallstrom J, Kiviloog J, Lundback B (2001) Environmental tobacco smoke exposure during childhood is associated with increased prevalence of asthma in adults. Chest J 120: 711-717.

33. Asthma Burden Report (2012) Utah Department of Health.

34. Weiss ST, Raby BA, Rogers A (2009) Astha genetics and genomics 2009. Curr Opin Genet Dev 19: 279-282.

35. Kuiper S, Muris JW, Dompeling E, van Schayck CP, Schönberger HJ, et al. (2006) Association between first-degree familial predisposition of asthma and atopy (total IgE) in newborns. Clin Exp Allergy 36: 594- 601.

36. Mingomataj EC, Xhixha F, Gjata E, Hyso E, Qirko E (2008) Prevalence of a family history of atopic disease among 3 generations of atopic respiratory patients in Tirana, Albania. J Investig Allergol Clin Immunol 18: 190-193.

37. Altshuler D, Daly MJ, Lander ES (2008) Genetic mapping in human disease. Science 322: 881-888.

38. Howard TD, Koppelman GH, Xu J, Zheng SL, Postma DS, et al. 2002 Gene-gene interaction in asthma: IL4RA and IL13 in a Dutch population with asthma. Am J Hum Genet 70: 230-236. 